\title{
PROBLEMS AND PROSPECTS OF PROFESSIONAL ACTIVITY OF HIGHER EDUCATION TEACHERS
}

\section{Sushchenko A. V.}

\section{INTRODUCTION}

At the beginning of the XXI century, in the Ukrainian society there has arisen and is gradually growing the need for the formation of a new generation of higher education teachers, being able to revive the trust in the system of higher education in a long person-oriented interaction with higher education students, to support the harmonious and comprehensive development of youth in the conditions of the information society.

The long and unwarranted ignoring by the state of the pedagogical capabilities of higher education teachers in the formation of a physically and mentally healthy nation has led to the fact that on the background of the socio-political and economic problems in which Ukrainians already live on average 10-12 years less than the citizens of the European Union, the profession of a teacher in higher education gradually acquires the image of a "second-rate" one, and their professional training becomes a technology of «production of specialists in the best traditions of reproductive and supportive education».

Furthermore, in modern Ukrainian higher education there are many habitual and well-established forms, methods and means of teaching, regulated by regulatory and legal documentation and strongly supported by the force of established traditions and standards of the profession. Their creative, sometimes illegal, but evolutionarily inevitable interpenetration, coalescence and modification is a natural process of selecting the best options, determined by the changing tasks and goals of each particular higher educational establishment and teacher.

In this regard, it's worth reflecting on the future characteristics of higher education in Ukraine in order to form a comfortable and wellthought-out position with respect to a possible modification of the role, mission and functions of higher education teachers in the conditions of the information society. The substantive basis of such reflections are some generalizations of the author's pedagogical experience within the 
framework of training of higher education teachers, that has been carried out in the Classical Private University from 2004 to 2019 (Ukraine, Zaporozhye).

The purpose of this article is to present the author's forecasts regarding some important trends in the professional activitiy of teachers in higher education of the future based on the processes that have been already manifested.

\section{Important trends in professional activity of higher education teachers}

The author's observations of the existing situation in higher education allow us to explicate a number of interesting contradictions that directly relate to our near future, in particular between:

- the traditionally stable desire of the teacher to be the main reliable source of information for the student and the growing technical capabilities due to which his/her immediate presence and contact are often not mandatory;

- the permanent growth of opportunities for an objective assessment of the quality of pedagogical work using statistical analysis of feedback parameters (for example, thanks to click technologies, anonymous sites where every student can leave a real comment about own impressions of the teacher's work) and the absence of a valid mechanism for the correlation of teaching skills with his/her salary;

- the abstract nature of the correlation of the pedagogical work results with the economic benefits of scientific and teaching staff and concrete readiness, interest of business in knowledge, skills, values and competencies of graduates of higher educational establishments;

- declaring in the Bologna agreements the need for a mobile, eventful, mutually beneficial exchange of teachers in the higher educational establishments of the European Union and the lack of a real economic and sometimes regulatory and legal opportunity to carry out a qualitative improvement of own professional skills in the leading universities;

- the growth in the number of multimedia models of higher education in developed and developing countries, the increasing educational role of electronic media and the imperfect legislative basis in this sphere, the inability to quickly learn this skill for all higher education teachers. 
The above and many other contradictions generate local energy for overcoming the crisis, in which there is not always a place for the officially declared policy of higher educational establishments, but there is always an opportunity to make a significant correction in the organization of the real pedagogical process.

For example, many experts consider the transfer of energy of pedagogical processes to the zone of autonomous educational behavior of students, their independent work to be among the already long-term trends ${ }^{1}$.

In order to, first of all, save money, higher educational establishments are trying to transform many types of students' educational work into an independent plane, using educational platforms such as the Learning Management System (LMS) Moodle, and others.

Their role in education is gradually growing, displacing not only expensive paper carriers, but also many "informative", low-level types of classroom work. Indeed, is there any sense in ineffective reading from a book of new information, during which the teacher did not receive a single question from the audience, did not respond to the obvious loss of interest and a decrease in the level of understanding of information?

Would it not be more effective to replace such a lecture by watching the best analogues in youtube-format, for example, the Nobel laureates recorded on video using expensive demonstration equipment, 3D graphics, etc.?

Taking into consideration the growing sentiments of "saving", such a solution will probably come, perhaps, at the level of state standards, which means that over time, every student, regardless of the country of residence, will be able to have access to the world's best teachers, academic and scholars on any problem or discipline.

It's a matter of fact that that the war for the minds, feelings and attitudes of modern students is gradually moving into the Internet environment - a convenient, capacious, bright, comfortable. It is fair to say that our students "have been living" in it for a long time, and computer processors in various forms gradually become an extension of their body, sense organs and brain.

1 Солдатенко М. М. Теоретико-методологічні основи розвитку самостійної пізнавальної діяльності майбутнього вчителя : дис. ... д-ра пед. наук : 13.00.04. К., 2006. 427 c. 
That's exactly what Ray Kurzweil, one of the most successful futurologists of our time, said, when he foretold that by 2030-2035 there would begin a gradual merging of human organisms with powerful nano-computers, thanks to which our life would last indefinitely long, and most of the processes would be managed by several grams of inanimate matter, created by us and sometimes thinking for us $^{2}$. it is fair to say that it is fair to say that it is fair to say that it is fair to say that it is fair to say that

Clear for professionals, but still latent for the general public, the problem of saving expensive time of teachers, against the background of social, demographic and economic troubles that have plagued our country since its inception, requires an immediate response and a wellthought-out solution right now. At the same time, the need to reduce the cost of the educational product by reducing the share of "manual labor" or its cost becomes natural, as well as replacing a person in all types of industries where it is possible.

Presenting the results of own research, most of which is at the interface between the still unshaped theory and the practice that has not been verified by the prolonged experiment, I would like to outline the essence of possible changes in the work of higher education teacher in the context of globalization and the informatization of the world.

An important change concerns the mission of the higher education teacher's classroom work. In the new conditions it can be expressed in the following hypothesis: a successful teacher in the higher education of 21 century will gradually change the style of classroom work from "informing" to "encouraging," "advertising," "motivating," "inspiring" one.

The main goal of this work will be the student's desire and ability to act independently. This trend is increasingly noticeable in private higher educational establishments, where there is practically no financial support from the state, and rich investors and mecenats are in no hurry to invest in the future of the educational and scientific sphere, since in the conditions of high competition for the survival and prosperity, people with a limited time resource and relying on their independent work with a predominance of the distance form of interaction have been invited to

2 Predictions made by Ray Kurzweil. URL: http://en.wikipedia.org/wiki/ Predictions_made_by_Ray_Kurzweil. 
study by Ukrainian higher educational establishments over the last $8-10$ years.

It is likely that with the liberalization of the regulatory framework for the organization of the educational process, licensing regulations and the rules of accreditation of specialties, the transfer of the function of control over the results of the educational process onto the shoulders of independent and objective professional communities, this solution will become the basis for a substantial modernization of higher education.

Today, unfortunately, there is a growing and expanding category of people who are undecided professionally, who are only interested in obtaining a higher education diploma and obtaining a formal right to hold one or another post.

This phenomenon is peculiar not only to the Ukrainian mentality and is the subject to separate discussion, but already signs of a way out of the current situation are outlined. Market relations in this sense inevitably separate professionals and amateurs with diplomas.

Currently, in general, very few people would think of hiring a person to provide any service, based only on the diploma. As for the survival of higher educational establishments, here, given that in 19952001 the birth rate of children in Ukraine at the beginning of the 21 century has permanently fallen ${ }^{3}$, most likely, it will be decided on the liberalization of state policy in the field of certification of specialists.

Therefore, many other extra-university factors will be involved, and higher educational establishments interested in increasing the value of a diploma will be forced to compete for a client on the basis of proposals of a higher quality of education.

In these conditions, in addition to the usual and well-established forms of academic work, those ones that would have been impossible 20 years ago due to the lack of certain technological resources and not expensive but adequate to the requirements material base, break into the standards of modern professional education.

Trends in the modification of the profession of higher education teacher, observed and understandable on the basis of a real pedagogical experiment in the Classical Private University, allow us at this stage of the experiment to confirm the hypothesis of the reasonability of changing the "informative", "mentoring" teaching style to "encouraging", "suggestive", "persuading", "advertising" or "inspiring" one.

\footnotetext{
${ }^{3}$ Державна служба статистики України. URL: http://www.ukrstat.gov.ua/
} 
This solution will allow most teachers to comfortably fit into the already visible model of the future higher education, in which a significant part of the work will be shifted onto the shoulders of increasingly intelligent, convenient and inexpensive machines, and the main demanded ability of the "classroom" teacher will be the ability to involve students of different specialties in a prolonged self-study on the methodical base of universities.

Thus, to "light the fire" of motivation to study independently, with minimal effort and time in a classroom format, promote local resources of support for curricula, and then continue to manage students' independent learning activity in the distance format - this is the model of future teaching.

An important characteristic of such a future, following the logic of the universally dominant "Chinese" strategy for the production of material and ideal goods, will be the cheapening of professional training.

That is what will entail the high competitiveness of the "encouraging" rather than the "informing" teaching style.

Really, a whole pleiad of skilled teachers is born before our eyes, behind whose back, due to the current economic inexpediency, there is practically no real empirical science, but there is "inspiring", "encouraging" competence that is capable, based on high emotional intelligence, personal charm and artistry, to accomplish at least one task set by management everywhere to recruit and retain students within the framework of a contractual relationship with a higher education establishment.

Thus, in the not too distant future, according to our forecasts, there will be a certain separation of forms of labor and cooperation. Some teachers-scholars will get knowledge - others will popularize and transmit it. Such a practice, based on healthy competition, has long existed in the world, where a maximum of one percent of the population creates technologies, standards and algorithms, and the remaining 99 percent use them, to our general pedagogical joy - still in a creative form.

Getting back to the experimental training program of higher education teachers in the Classical Private University (Ukraine, Zaporizhzhia), in which most of the energy of the pedagogical process has been transferred to the distance format, the zones of greatest difficulties can now be identified: the absence of prolonged personal contact with "knowledge carriers", difficulties with the acquisition of 
most unthinking skills and the general lag of specific professional kinesthetic culture.

I would like also to highlight the main positive aspects: increased access to educational resources; the involvement of people living in remote areas through the use of the Internet; producibility in assessing a significant part of the cognitive component of learning; minimum level of human on human violence; creating a competitive environment for the emerging market of teachers of the "inspiring" category.

The last thesis in regard to the development of the higher education system is of great importance. As mentioned at the beginning of the article, the teacher today is in a lowly competitive environment and is not formally interested in the results of his/her work. Increasing opportunities for his/her fair and accurate assessment through the analysis of feedback from consumers of services allows us to hope for the creation in the near future of a system of direct behavioral-oriented reinforcement of the teacher's efforts in showing pedagogical skills in the classroom and some other work.

Content analysis of one of the most popular, although not perfect, sites dedicated to the creation of a teacher's rating can in many ways serve as an example for the vision of the future ${ }^{4}$. The opinion of the consumers of educational services themselves - students of different specialties - makes it possible to track the latent dynamics of satisfaction with various aspects of the pedagogical work of higher education teachers. At the same time, this can be done on the scale of almost the entire former Soviet Union. By the way, among the positive qualities that have recently dominated in the comments of students (and maybe teachers, the survey is anonymous), the leading ones are those that suggest the ability to optimistic, uplifting, supportive, facilitative teaching:

- «Very positive classes, after which you want to change something not only in yourself, but also in the outside world»;

- «The teacher is SUPER!!!!!!!!!!!! Cheers up in every class!!!»;

- «Unforgettable classes, even sitting at 8-9 with pleasure! And all because you like recharge yourself with his/her positive energy».

These and many other anonymous statements are of interest for analysis and self-reflection, that gives in general the hope for a gradual approach of the teaching profession to higher competitiveness and

\footnotetext{
${ }^{4}$ Рейтинг преподавателей. URL: http://www.studzona.com/teacher.
} 
measurability, which is of great importance in the era of market relations. At this stage, a significant problem is the intensity with which students take notes. Unfortunately, it is not enough. Ideally, the teacher should have the opportunity to analyze the results of each class, which is quite possible if there are specially equipped classrooms in the "here and now" version, as well as taking into account the interests of other potential participants in the assessment of pedagogical work, namely:

- the potential employer and his goals, which may have significant contradictions with the existing theory and practice of professional training, standards of educational qualification characteristics, etc.;

- the head (owner) of the educational establishment who pays the teacher a salary and is often interested in profit, which is formed in a strong dependence on the quality of the teacher's professional activities;

- student's relatives who, as a rule, pay for his/her education and are not indifferent to the process and results of professional training.

Consequently, the slow but steady changes taking place in the sphere of higher education make it possible, at the local experimental level, to track some trends in the professional activities of higher education teachers, one of which is the increase in the quality of feedback from educational service users. Analogues of the future technology of fixing and processing feedback may be the already working voting system during political and civil talk shows on television or radio, for example, the TV program Shuster-Live, once popular in Ukraine, in which you can see samples of future models of the classroom work based on instant feedback by voting.

\section{Problem of adaptation of Ukrainian higher education teachers to a multicultural European educational space}

Exploring the possibilities of harmonious integration of the Ukrainian higher education teachers to the European educational industry is considered by us as a prerequisite for national professional education reform. Such a position is determined, first of all, by the generous economic and multicultural interest of «doers of good and eternal», the great attractiveness of the very idea of our state movement to Europe.

It is known that in Ukraine, as in the vast majority of the European Union countries, there live the people, who are the bearers of numerous 
forms of ethnic culture, in which every professional should be up to speed on. Taking into account the peculiarities of every nation mentality during the creation of pedagogical processes can become a universal adaptogenic factor that will make it possible to realize effectively the great potential of Ukrainian ethnic and classical pedagogy in a new society.

The works of A. Bolshoy, E. Vasiliev, Z. Hasanov, O. Hurenko, L. Zhdarkin, V. Zasluzhenyuk, Z. Ihushkin, O. Korzhov, G.Mararenko, O. Opalenik, V.Prysakar, Y.Talybov, N. Khrystych and others are devoted to the research of teachers skills in work with multinational student groups. In these works they consider the preparation of specialists in close connection with their personal and ethnic as well as professional self-identification. A critical analysis of already known ways to solve the problem shows that the existing theoretical and methodological concepts of this phenomenon are mostly partial, conceptually uncoordinated and often contradictory.

We believe that the peculiarities of training of higher education teachers for such work have not yet found a complete coverage in scientific literature, and, therefore, have been chosen for research as unresolved theoretical and empirical problem. The purpose of this chapter of a monograph is to reveal the peculiarities

of adaptation of Ukrainian higher education teachers to the multicultural European educational space.

Usually such problems in higher education are solved in a proven way - the introduction of a special course to curriculum, or the inclusion of some elements of the problem to the content of special disciplines and pedagogical practice. Our perceptions about such training are not the exception, but it has had some originality from the very beginning.

To begin with, monocultural isolation of future masters in pedagogy of higher education has become a serious disadvantage. To some extent it comes from the desire of present day students to study the history, culture and traditions of career building in their country as deeply as possible.

Of course, this deserves the comprehensive support, but granting Ukrainian (or any other) "national-pedagogical" traditions and standards the status of universal, common to all mankind or world-wide is the undisguised discrimination of other views. 
Secondly, our vision of solving the problem of the teachers training for work in a multicultural space was a result of theoretical understanding of its essence and content and was considered as creation of social, pedagogical and psychological conditions for realization by the future teachers those makings and opportunities, that an extra-national and universal character. The peculiarity of our concept of the teachers training is that it was carried out during performance of professional duties and simultaneous study for a master's degree in "Higher education pedagogy".

The concept of training was defining approaches to understanding the peculiarities of pedagogical activity under the conditions of the multicultural space as to purposeful revival of the teacher's extranational humanistic values, which are the most powerful "engine" of his/her professional self-determination and self-realization.

The last phenomenon is based on the understanding of pedagogical activity under the conditions of multicultural space as a definition and maintenance of own position by the teacher, founded on the unconditional acceptance of the uniqueness of every person, regardless of ethnicity, as the highest value, considering that the teacher himself/herself should be such value for all subjects of the pedagogical process. We introduce these ideas in the process of intra-university training and giving support to teachers at the initial stage of pedagogical activity on a principles of humanism, which, by all means, falls within the definition of "innovative activity".

Both spontaneous and organized previous attempts to actualize in a scientific way the international and ethnic potential of each teacher in pedagogical activity using the administrative resource proved the failure of such approach. Therefore, our concept is based on the idea that such innovation should be supported not only by the strongest external motivation and incitements for changes in one's work, but also by real results for a teacher, whose activity is determined by the needs of happiness, the way to which lies through self-realization in the chosen profession, also under the conditions of much more advanced and developed european educational space.

Thus, originated with the fundamental need of the teacher, the process of objectification of his/her essential existential vitality, which happens due to own internal and external activity, is the background on 
which the aggregate picture of the teachers training under the conditions of a multicultural space should develope.

It should be noted that the effects of this training largely depends on the "starting" preparedness of all subjects of the pedagogical process: the level of pedagogical skill, the quality of own "polyethnic" potential, the level of personal and professional self-realization in the profession, etc.

The low level of manifestation of one of these factors reduces the effects of the other one. In the educational sphere of Ukraine, the search for algorithms of such training is restrained by the absence of a complete concept of forming ethnocultural competence of students of pedagogical universities in a multi-ethnic environment as well as contradictions, that have place in the state between next cases:

- the global need for movement to the European community in all spheres of life and local lobbying of the priorities of a purely local development of higher education establishments (it does not necessarily mean that our education is worse);

- a modern, generally accepted view of the effects of democratic education and the authoritarian tradition of performing professional and pedagogical duties in the Ukrainian higher education (corruption, overregulation, low level of academic freedom, priority of "preventing failures" motivation);

- the long-term formation of a master-teacher and quick elimination of his socio-economic status by the state and society (wage in comparison with the medium wage in Europe is several times smaller);

- the ideas of humanism regarding equitable living conditions, justice and brotherhood in a democratic society and low socio-economic competitiveness of the teacher among other categories of employees;

- the rapid development of requirements to the level of pedagogical competencies and the inability to achieve justice in assessment of quality of his/her function realization, the completeness of his/her potential diclosure.

In the master degree program in specialty 011 "Educational, pedagogical sciences" (educational program "Pedagogy of higher education") together with getting knowledge concerning pedagogical ideas and views of various professional-pedagogical subcultures living in Ukraine and Europe, it was also supposed to acquaint students with specific pedagogical practice. 
The acquisition of organizational and pedagogical as well as research skills by future teachers in higher education was promoted by various forms of work and teaching, including acquaintances and Skypeconferences with ethnically and culturally different European universities, conversations with students and their parents, who have a pronounced ethnically dependent culture, participation in conducting festivals of friendship, organized by numerous national-cultural communities.

The only but substantive restraining factor in the training process remains, first of all, the lack of the financial possibility to get pedagogical practice in the higher educational establishments of other countries, although the first attempts to cope this problem appear due to the so-called "double certification".

Therefore, the combination of the master degree program study, built on a cross-cultural basis, and the organization of ethnopedagogical studies of students provided the organic unity of theoretical studying with the practical preparation of the European universities teachers for the implementation of diagnostic-prognostic, educational-edifying, constructive-organizational tasks; it contributed to attracting students to research work in the field of higher education; it stimulated the development of their intercultural thinking, professional interest in the pedagogical traditions of different nations, tolerant attitude to the ethno-cultural diversity of modern society.

In this very diversity people of one nation become interesting to others. The fact remains that German is interesting to the Frenchman, as long as he is German.

By emphasizing such a difference and dissimilarity, developed nations became able to understand that we should not compare each other from the "well-bad" point of view. The self-sufficiency and success of both nations (in the given example) are beyond doubt.

The category "perspective - not perspective" looks like more attractive system of coordinates. What useful things can you take for your life from the experience and traditions of another nation? What will life become in case of using foreign pedagogical technologies in our field? These are the questions that should confuse the mind of a professional teacher.

It is known that multiculturalism helps, first of all, to save and increase the diversity of cultural values, norms, patterns of behavior and 
forms of activity; and secondly, helps to form both the cultural identity of the individual and understanding of the cultural diversity of modern societies, the inevitability of cultural differences between people.

A. Parnell-Arnold considered polyculturalism as the study of the value of difference, the opportunity to represent the nation and the world society as a mosaic, in other words that's the complete inclusion of individual in the cultural interaction process without reducing the cultural difference of every culture ${ }^{5}$.

The multivariance of the available and hidden essential power, created by the of events of every teacher's life, peculiarities of family education, genetic instincts, social environment and own efforts determine the multivariance of the ways of the teacher's self-realization.

As for all working university teachers, who also claim to work in the European space of higher education, the starting points for developing the process of their adaptation during the intra-university raising of qualification, our experience has made it possible to build it on the principles of the following attitudes:

1. The discovery of the "multicultural" potential of a teacher depends predominantly on himself/herself, on his/her life approach activity, on purposes set by the teacher. This is not only the consequences of his/her special talent and skills. All possible successes in pedagogical activity depend on the teacher's ability to materialize nonnational purposes of personal development, education and development in his/her professional activity.

2. Teacher's desire for harmony with his existential and ethnic values and internal convictions begins with understanding of his own opinion, the causes and conditions of its emergence. Having changed the quality of our thinking, we also change the quality of our life, meaning that changes in external experience are related to the internal changes. Control over own opinion is hypothetically unlimited.

3. The subject to objectivation there is only that usable potential essential acquired vitality, which we believe in, and which became our mindset, because our convictions and attitudes unconsciously carry out a separation of constructive and destructive things in relation to other people, to the profession, culture, information.

${ }^{5}$ Parnel - Arnold A. Melting pot to multicultural society // English Teaching Forum, 2000. http://exchanges.state.gov/forum/journal/ 
4. Patterning of the life and professional perspectives of teacher's personality can be created on the basis of his/her consistent, step-bystep, controlled getting up to the imaginary pinnacle as his/her existential mission and through actualization of significant real situations (work in prestigious educational establishment of Europe). The result of this stage should be teacher's awareness of what awaits him on the way towards reaching the goal, of what is to be done now to get success. This work will be continued, but at the level of "actions and deeds", when the teacher has a clear idea what he/she has to refuse to on the way towards reaching the goal, what new features should be acquired,that is reflected in actions and deeds.

5. Self-realization process of multicultural potential and taking into account national peculiarities of pedagogical process participants in professional activity begins there - and only there - where there is an orientation to another person whose life, thoughts, feelings and cultural characteristics are of the same value as the own ones. This will definitely increase the range of spiritual connections in the process of teachers' entering into new social situations in the process of choice of the professionally successful individual role.

Of course, the professional training of each individual teacher, much less further integration in the unfamiliar environment, proceeds in different ways. Even with a relative simililarity of external life conditions, age, sex, etc., the subjective-activity changes happen to individual teachers at different rates: at each stage of life they differ not only in quantitative but also qualitative indicators and characteristics.

That's why the professional achievements, conditions for the forming and development of which are formally very similar, turn out to be significantly different. These differences are first of all caused by the teachers' natural potential. It is the thing that determines the nature of teachers reaction to external influences, including administrative, social, and political ones. However, the further pedagogical activity of the individual teacher consists of the consequences of these reactions, because it is the expression of his/her specific needs and desires as a whole.

The teacher should not be completely torn out of his ethnic environment, on the contrary, as a result of existing contradictions between the focus of his vitality and the objective order of things in the Ukrainian education, he/she constantly shows an activity to an imperfect outside environment. This thesis relates, to some extent, to the 
implementation of the principle of multiculturalism, because the pedagogical activity of higher education teacher, which takes into account the polyethnic peculiarities of student youth, exists or has existed mostly in local experiences of some higher educational establishments of the country, and is considered an ideal, which has not yet been achieved in scope of Ukrainian educational space.

\section{CONCLUSIONS}

We got used to the fact that higher education teachers can and should live and work for a long time. Over the years, their value in prolonged saturated contact has not been devalued, and their thoughts continue to fill the inner world of their students. The reason for confidence that it will always be so lies in the peculiarities of the profession. It is one of those few professions, in which the person is charged with the obligation to "mutually penetrate", mutually enrich with the feelings, thoughts and actions of another person.

At the same time, the value of such a teacher with the fall in the proportion of direct human contact "teacher-student" inevitably grows. When improving the technique of such "mutual penetration" as a component of pedagogical skills, it is very important to avoid cliches, to form your own style of using all expressive means, with the help of which the teacher achieves originality and target impact. Nevertheless, steady technical progress forces us to make some useful generalizations concerning the teaching work that will be in demand in the near future:

- the degree of saturation of interpersonal contacts "teacherstudent" will fall, that will force the need to shift the emphasis of classroom work from the "informative" "mentoring" category to "facilitative", "inspiring", "encouraging" one;

- transferring the energy of study to the personal responsibility of students determines the need for all teachers, without exception, to develop specific skills for the maintenance and support of this work in the zone of autonomous behavior;

- automatic analysis of feedback signals, together with thoughtful control and monitoring of the cognitive, emotional and behavioral areas of future specialists, will put the teacher in conditions of tough but fair competition in the labor market.

Taking into account these and other trends, we have determined that the most up-to-date direction for the training of future masters is 
the development of their sensual and communicative culture. In practice, this integrative set of pedagogical values and patterns of professional activity is directed at the development of the capacity of higher education teacher, to sincerely, empathically and creatively broadcast his/her feelings and thoughts, creating the appropriate interrelations and interaction between the subjects of all ethnic groups of the pedagogical process, the manifestation of individual identity, the removal of fear of a possible failure.

Ethno-ideological self-determination of the teacher is another aspect of the training of future higher education teachers, that has the prospects for modernization. This aspect presupposes: awakening of deep thinking, the desire to confirm or refute the authenticity of phenomena or statements, prove their falsity or expediency, make a conscious choice and turn it into an element of their own beliefs; stimulating reflexive perception of new information, transferring it in exciting forms through the catharsic expression of emotions in the process of co-creation; development of emotional-value attitudes to knowledge, the need to use these knowledge; induction to transformational thinking, comparisons, generalizations, thoughts and empathy.

Cultivation of multiculturalism is as long process as the cultivation of other human qualities. Person can not immediately become multicultural after reading the book, or having listened to a course of lectures on this issue. Every student goes through several degrees or levels during his/her multicultural formation: tolerance, understanding and acceptance of another culture, respect for culture and the acceptance of cultural diversity.

Actually existing as a carrier of many cultures, every teacher, based in his/her profession on the principle of multiculturalism, expands the possibilities of forming a personality with a planetary thinking, humane, tolerant, objective, ready for creative cooperation, capable of independent choice in assessments and actions, to the realization of universal values and the creation of new ones, responsible for the progress of the entire world community.

In fact, this article is part of setting of the problem of seeing the future of an ideal Ukrainian university and Ukrainian teacher. It does not in any way pretend to objectivity and accuracy in the assumptions put forward, but in future it allows us to understand more deeply and decide in which system of higher education you and I will soon have to work. 


\section{SUMMARY}

Ukrainian higher education in the late 10's of the 21st century, was faced with numerous innovations, determined by the entry into the European educational space. Conducting a large-scale pedagogical experiment on the organization of the educational process in the higher educational establishments of the III-IV accreditation levels according to the standards of the Bologna Agreement, highlighted a number of interesting trends. On the one hand, there appeared supporters of the long-awaited European higher education, in which the best higher planets were present, on the other hand, there were those who questioned the expediency of such a step for the majority of young Ukrainians and insisted on the existence of great difficulties in the aspect of adaptation of subjects of Ukrainian educational culture to multiculturalism of Europeans.

The article substantiates that the most highly anticipated moment in the history of Ukrainian higher education teachers, namely an attempt to study and work abroad, has become a reality for mass consumption, not just the cause of elites. For these reasons, a number of difficulties and prospective ideas are presented, the implementation of which has an actual-perspective character for the theory and history of professional education. It is shown that one of such problems, according to pilot and individual fundamental researches, is ill-preparedness of our students to accept all the wealth of multicultural forms that exist in the European Union.

The article discusses the current and prospective problem of the adaptation of Ukrainian students to the multicultural conditions of study in the European educational space. The author presents theoretical positions regarding the creation of pedagogical conditions for such an adaptation within the framework of existing pedagogical processes. The conclusions of the pilot pedagogical experiment of the corresponding training of students of the specialty "Higher education pedagogy" are presented.

\section{REFERENCES}

1. Солдатенко М. М. Теоретико-методологічні основи розвитку самостійної пізнавальної діяльності майбутнього вчителя : дис. ... д-ра пед. наук : 13.00.04. К., 2006. 427 с. 
2. Predictions made by Ray Kurzweil. URL: http://en.wikipedia.org/wiki/Predictions_made_by_Ray_Kurzweil.

3. Державна служба статистики України. URL: http://www.ukrstat.gov.ua/

4. Рейтинг преподавателей. URL: http://www.studzona.com/ teacher.

5. Parnel - Arnold A. Melting pot to multicultural society // English Teaching Forum, 2000. http://exchanges.state.gov/ forum/journal/

Information about the author: Sushchenko A. V.

Doctor of Science in Professional Education, Professor, Head of department, professor of Education and Management of Educational Institution, Classical Private University 70b, Zhukovskoho str., Zaporizhia, 69002, Ukraine 